\title{
ELEMENTOS PARA UNA ANTROPOLOGÍA DEL CINE: LOS NATIVOS EN EL CINE FICCIÓN DE CHILE
}

\author{
TOWARD AN ANTHROPOLOGY OF CINEMA: \\ NATIVE IN CHILEAN FICTION FILM
}

\author{
Francisco Gallardo ${ }^{1}$
}

\begin{abstract}
El cine ficción es uno de los medios de comunicación visual de mayor influencia en la circulación de valores y creencias en el mundo contemporáneo. Se trata de una práctica cultural de extremo control, planificación y manipulación audiovisual que ha permanecido en los márgenes de la preocupación antropológica. Sin embargo, nuevos intereses relativos a la comprensión de los modos de ver nos han permitido indagar con cierta profundidad en el funcionamiento de este dominio y sus artefactos visuales. En el presente artículo se describen los dispositivos y procedimientos visuales relativos al cine ficción chileno, en particular aquel que ha introducido en sus obras de modo protagónico la imagen de los nativos de Chile. Nuestros resultados sugieren la presencia de una estrategia cultural cuyas representaciones sólo tratan formalmente con la diversidad cultural, un recurso audiovisual que ha favorecido el establecimiento de un modo utópico de imaginar al "otro" y su mundo social.

Palabras claves: antropología visual, cine ficción, modos de ver, representaciones del nativo.
\end{abstract}

The cinema is one of the visual media of more influence in the circulation of values and beliefs in the contemporary world. It is a cultural practice that has remained in the margins of the anthropology. However, new relative interests to the understanding in the ways of seeing, it has allowed us to investigate with certain depth in the operations of this domain and their visual devices. This article described the devices and visual procedures to native representations a Chilean cinema fiction. Our results suggest the presence a cultural strategy whose representations don't try with the cultural diversity, but rather they appear as a utopian way of imagining the social world.

Key words: Visual anthropology, cinema, ways of seeing, representations of native.

El cine ficción es uno de los medios de comunicación visual de mayor influencia en la circulación de valores y creencias en el mundo contemporáneo. Se trata de una práctica cultural de control, planificación y manipulación audiovisual que por largo tiempo ha motivado a historiadores del arte (Arnheim 1986[1957]; Panofsky 2000[1947]), semiólogos (Metz 2002a, 2002b; Stam et al. 1999; Wollen 1972) y críticos literarios (Jameson 1984, 1995) ${ }^{1}$. Estos y otros analistas (p.ej. Nichols 1985; Rollins 1987) han demostrado de manera elocuente la importancia de este medio en relación con el imaginario y la vida social, sin embargo, es un tema que ha permanecido alejado de los intereses de la antropología. Quizás la única excepción sea el trabajo de Hortense Powdermaker (1955), quien realizó una cruda, pero elegante etnografía del mundo de Hollywood de la década de 1940. Ella percibió con claridad la relación entre el proceso de producción, el contenido y los espectadores, al punto de acusar a la industria del cine de promover el totalitarismo: "En Hollywood, el concepto del hombre como criatura pasiva que es manejada por otros se extiende a los que trabajan para los estudios, a las relaciones sociales, a los espectadores en las salas cinematográficas y a los personajes de las películas" (Powdermaker 1955:345).

$\mathrm{Al}$ ocuparse del sistema social de producción cinematográfico, Powdermaker realizó una contribución fundacional para una antropología del cine. Sin embargo, no podemos ignorar que cuando nos referimos al cine, necesariamente debemos tratar con las obras, esos artefactos visuales cuya principal característica es la de provocar la ilusión de realidad, desde la llegada de un tren hasta gente huyendo por las escaleras de Odessa. Sin embargo, se trata de un producto que no es el resultado de una misteriosa actividad, sino que algo realizado por y para seres humanos. En tanto manufacturas, las obras cinematográficas son el producto de un trabajo que es ejercido desde y sobre los imaginarios -esos paisajes construidos por aspiraciones colectivas

1 Museo Chileno de Arte Precolombino, Bandera 361, Santiago, Chile. fgallardo@museoprecolombino.cl 
(Appadurai en Mirzoeff 2003:55)- pertinentes a una época histórica y cultural, ellas "encarnan un modo de ver" (Berger 2002:16).

Desde un punto de vista cultural, cabe poca duda que el cine objetiva, refleja y amplifica en imágenes y sonidos, creencias y valores dominantes, emergentes o residuales ${ }^{2}$. El cine objetiva, porque crea unas materialidades visuales para aquello que en el imaginario era sólo escritura, noción o concepto cultural. El cine refleja porque tiene como punto de partida el material disponible en el imaginario de la época de su realización. El cine amplifica el imaginario, porque los instala en el dominio colectivo, en las diferentes audiencias a las que está dirigido.

Esta relación de necesidad con los imaginarios de una época es el producto de una constricción sobre el acto creativo, pues la mayoría de los realizadores trabajan sobre sus materialidades audiovisuales para asegurar una eficaz comunicabilidad entre sus obras y las audiencias. Por esta razón, son muy pocos los realizadores que están dispuestos a abandonar los estereotipos o convenciones del medio, aunque sabemos que no son menos quienes poseen la habilidad de instaurar nuevas convenciones comunicativas, sean estas al nivel de la imagen o del relato audiovisual.

En el presente trabajo, exploramos el potencial analítico de una antropología del cine orientada al descubrimiento de ese conjunto de disposiciones para la acción que son constitutivos de un modo de ver. Conjunto de reglas cuyo contenido cultural está firmemente enraizado en nuestra historia social reciente, discursos cuyo carácter utópico e ideológico han materializado el fracaso de un tipo de imaginación social futura. Y es precisamente este proceso, el que ha favorecido el modelado de una imagen del nativo como el reverso positivo de un nosotros, que en las obras analizadas se expresa como una crítica a nuestros propios modos de convivencia con la naturaleza y la sociedad. Un tipo de práctica visual que al no superar la mismidad, ha erradicado al "otro" de su presencia y actualidad.

\section{Los Nativos en el Cine Ficción Chileno}

El cine en Chile tiene una larga historia y se dio inicio con Un Ejercicio General de Bomberos, un corto de tres minutos que se estrenó en Valparaíso el 26 de mayo de 1902, seis años después de la primera proyección de los hermanos Lumiére en París (Godoy 1966; Muesca y Orellana 1998). El nuevo invento despertó el entusiasmo de realizadores y público, y hacia finales de los años veinte se contaba con cerca de un centenar de estrenos de cine mudo. Durante los años treinta se introdujo el sonido, pero el número de las producciones declinó. Sólo fue hacia los años cuarenta y cincuenta que éstas volvieron a ser numerosas, época en la que la comedia y el drama le llevaron a su mayor expresión audiovisual. Hacia los sesenta, período de gran efervescencia social, se inaugura un nuevo modo de ver cinematográfico, estilo cuyos efectos se observan hasta la actualidad. Influenciados por el cine europeo de posguerra, el neorrealismo italiano y la Nouvelle Vague francesa, los realizadores vuelven sus ojos hacia la realidad del mundo popular. Tres Miradas a la Calle (Kramarenko 1957), Largo Viaje (Kaulen 1967), Valparaíso mi Amor (Francia 1969), El Chacal de Nahueltoro (Littin 1969) y numerosos documentales son piezas maestras del advenimiento de este nuevo paradigma visual.

Los pueblos originarios no fueron de interés para este cine nacional y sus escasas alusiones fueron la mayoría de las veces marginales dentro de los relatos como La Araucana (Coll 1971) o Frontera sin Ley (Margas 1971). Tal vez las únicas excepciones sean dos películas mudas, Agonía de Arauco (Bussenius 1917), Nobleza Araucana (Idiáquez 1925), que aunque irremediablemente perdidas, sabemos trataban sobre el despojo de tierras sufrido por los Mapuche (Godoy 1966). Desde siempre el "otro" reivindicado por el cine chileno fue el proletario, el campesino o el sujeto popular (Peirano 2006). Se diría que para este cine el nativo no constituía un sujeto histórico claramente distinguible, pese a la arraigada creencia en el heroísmo y valentía de los Mapuche proclamada desde los libros de historia escolar. Fue sólo desde mediados de los años setenta, con el estreno de $A$ la Sombra del Sol (Caiozzi y Perelman 1974), que los nativos irrumpieron en la pantalla de manera protagónica, como sujetos activos de la narración fílmica. Este es un tema cinematográfico que con cierta modestia ha proliferado hasta la actualidad. Archipiélago (Perelman 1992), Wichan (Meneses 1994), Cautiverio Feliz (Sánchez 1998) y Tierra del Fuego (Littin 2000).

Todos estos filmes recrean algún acontecimiento histórico y tienen como punto de partida material documental, oral, escrito o visual. A la 
Sombra del Sol se basa en los recuerdos de la gente acerca de un crimen cometido por delincuentes en una comunidad indígena de atacameños (norte de Chile); Archipiélago hace referencia a los nativos fueguinos a través de la cita de un documental realizado a principios del siglo XX por el sacerdote salesiano Alberto de Agostini; Wichan basada en uno de los relatos del cacique mapuche Pascual Coña (2000[1930]), recogidos por el sacerdote Ernesto Wilhelm de Moesbach, en el sur de Chile; Cautiverio Feliz desarrollado a partir de la obra homónima de Núñez de Pineda y Bascuñán (1999[1674]), quien fuera secuestrado por los mapuche en el siglo XVII, y Tierra del Fuego que está inspirada en el libro de cuentos del mismo nombre, escrito por Francisco Coloane (1956), quien trabajó en las estancias ganaderas de la región.

\section{Cine Ficción y Construcción de la Imagen del Nativo}

Una obra de cine ficción es el resultado de un conjunto de tareas que (esquemáticamente) se inician con un guión (y en la actualidad un storyboard), una selección de actores, una búsqueda de locaciones y una adecuada ambientación (Chion 1992; Gamerro y Salomon 1993). A esta etapa prefílmica le sigue el rodaje, momento en el que se produce el material audiovisual que finalmente será utilizado en la edición o montaje (Eisenstein 1977; Pudovkin 1999; Villain 1994). Se trata de un complejo proceso en el que debemos necesariamente incluir: la publicidad, la crítica, el visionado y la vida de la obra luego de su estreno.

Respecto a las películas mismas, ellas no son el fruto del azar, sino por el contrario son resultado de una práctica de planificación, de control sobre el "lenguaje" cinematográfico, que en su aspecto más básico es un doble montaje de imagen y sonido. Parafraseando a Pudovkin (1948:26), si la cámara son los ojos de los espectadores, entonces los realizadores imprimen en ellos su visión, modelando planos (tiro de cámara), para luego estructurar escenas, secuencias y la película completa. El producto final adquiere una forma narrativa, una sucesión de eventos audiovisuales cuyo ritmo aparece ante los ojos del espectador como un relato (Bazin 1966; Bordwell 1996).

En este proceso de producción audiovisual, se ponen en juego numerosos dispositivos visuales y sonoros, todos al servicio de una retórica que hace de lo verosímil la base de este arte de la persuasión. $\mathrm{Y}$ es precisamente en estas decisiones de imagen, sonido y edición que las representaciones se vuelven visibles y ostentosas de sus orígenes históricos, sociales y culturales. Si bien el montaje tiene una definición técnica entre quienes practican el oficio del cine, se puede afirmar también que toda obra fílmica es el resultado de un montaje, algo que en nuestra lengua lleva por significado aquello que ha sido preparado para que sólo en apariencia coincida con la realidad. Por consiguiente, es en este dominio del proceso creativo fílmico, donde hay que indagar para aislar esas unidades significantes que constituyen el habitus del artista, ese conjunto de disposiciones para la acción (Bourdieu 1977).

\section{Montaje 1: la imagen}

La eficacia de una película está en su credibilidad, en lo verosímil de sus unidades audiovisuales, en su pertinencia con la realidad elaborada dentro de la película. Por esta razón, no nos sorprende que la mayoría de las películas estudiadas incluyan en sus repartos a los propios nativos como recurso actoral, un dispositivo que -según André Bazin, el más reverenciado crítico del cine- permitía obtener una "extraordinaria sensación de verdad" (Bazin 1966:444). Esta "sensación" o efecto de realidad, que dicho sea de paso no siempre es exitoso, ha favorecido especialmente a las películas $A$ la Sombra del Sol, Wichan y Cautiverio Feliz, pues independientemente de las capacidades actorales de los nativos, sus desempeños son inapelables. Aquí es el otro y no nosotros el que nos interpela desde la pantalla, por consiguiente se crea la ilusión de una presentación que cancela a la re-presentación, se encubre que la "verdad" del otro filmado es la "verdad" de aquel que está filmando. Sin embargo, no se trata de un engaño, pues sólo un ingenuo no comprendería que en todos los casos estamos en presencia de un ejercicio de honestidad, pues la verdad buscada no se funda en la ciencia o la historia, sino más bien en el estado del arte, el contexto cultural y el punto de vista del realizador.

Los nativos en el cine chileno han debido caracterizarse, han participado en un proceso que llamaremos de vestidura, concepto que alude a aquellas prendas o elementos de vestuario que van sobrepuestas a la vestimenta ordinaria. A la Sombra del Sol es la obra que permanece en el estado más simple de la vestidura, pues la mayoría de sus 
protagonistas luce sus trajes de época ordinarios en situaciones ordinarias. Wichan sigue de cerca estas convenciones de vestidura, pero a diferencia de $A$ la Sombra del Sol, los personajes mapuche lucen atributos tomados de las fotografías del siglo XIX y no son pocos los planos en que las acciones transcurren en asociación a viviendas tradicionales, utensilios de cerámica y telares artesanales.

Los filmes mencionados se acercan a las convenciones del realismo retórico propias del género documental, muy distintas a la puesta en escena de la película Archipiélago, donde los protagonistas son situados en el período de contacto, al igual como ocurre en Cautiverio Feliz y Tierra del Fuego. Fueguinos y Mapuche son también recreados de acuerdo a fuentes históricas, arqueológicas y etnográficas, como también a fotografías y material documental. Pero es en estas realizaciones que -por primera vez- se coloca énfasis en lo ceremonial. Parafernalias, atuendos, pinturas corporales se transforman ahora en un tipo de vestidura privilegiada, en signos emblemáticos de identidad. Si en A la Sombra del Sol y Wichan era el contexto el que contribuía a proporcionar los atributos de la alteridad (paisajes, viviendas y cotidianeidad), en estos últimos es en el sujeto donde se inscribe la diferencia, distinción cuyo exotismo visual se vuelve cómplice de esa condición mística que el mundo contemporáneo atribuye al nativo, al "otro" en general (Figura 1).

Paralelamente a la vestidura, es posible constatar un segundo procedimiento que llamaremos de investidura, pues confiere al nativo un tipo de dignidad en el orden de lo social. En las películas mencionadas, el modelado de este concepto aparece como una regularidad. Atacameños, Mapuche y Fueguinos rara vez trabajan, sin embargo, viven explícitamente en una abundancia o riqueza social. Ninguno de estos grupos aparece afectado por la hambruna o la miseria, sino por el contrario disfrutan de algún tipo de excedente económico, en especial Atacameños y Mapuche que aparecen en festividades donde no escasean los productos agrícolas y ganaderos que permiten el goce comunal (Figura 2). Los Fueguinos, probablemente por su condición de cazadores recolectores, no parecen

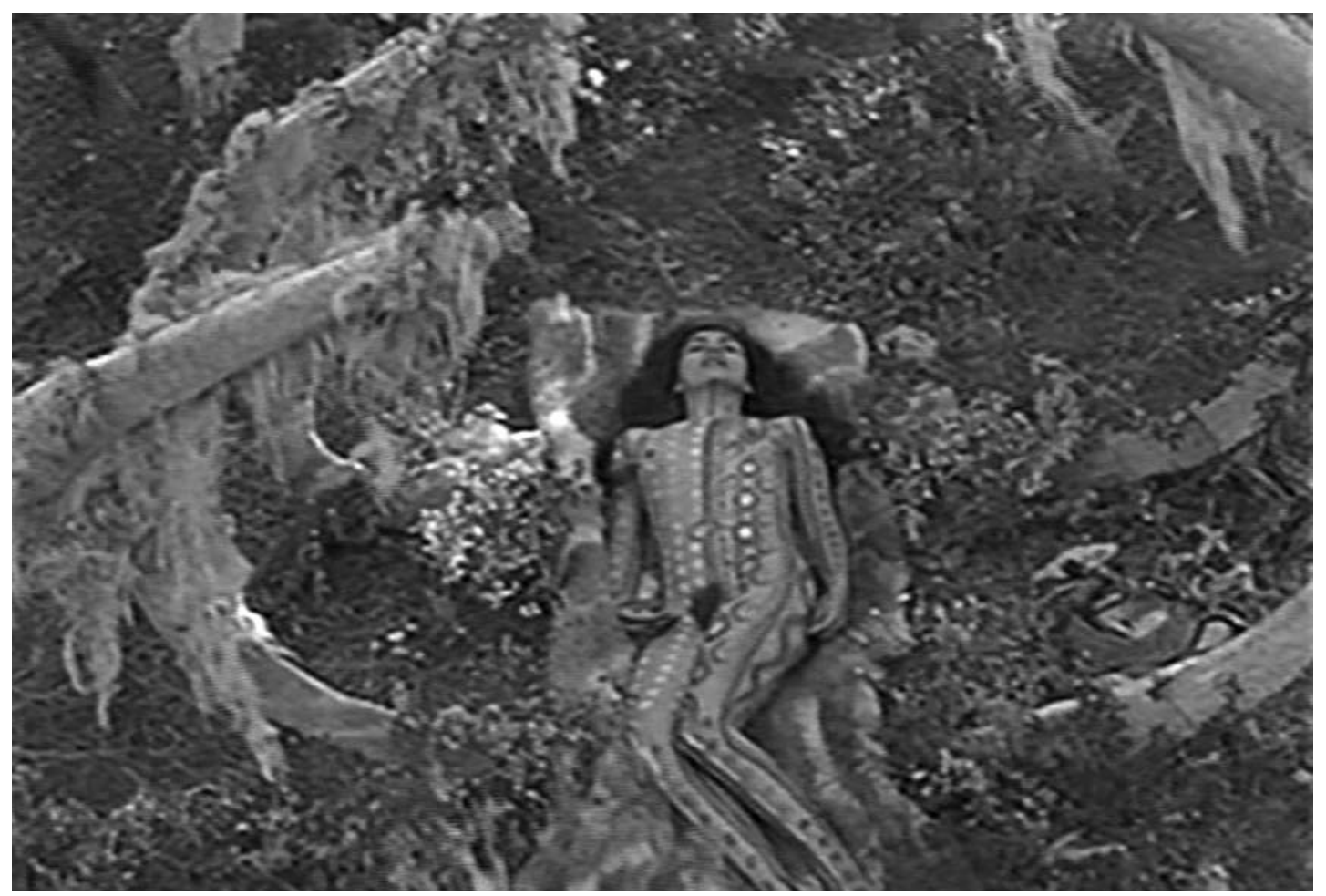

Figura 1. La actriz Tamara Acosta ataviada como “chamán” selk’nam en el filme Tierra del Fuego (Littin 2000). Actress Tamara Acosta costumed as selk’nam shaman in Tierra del Fuego film (Littin 2000). 


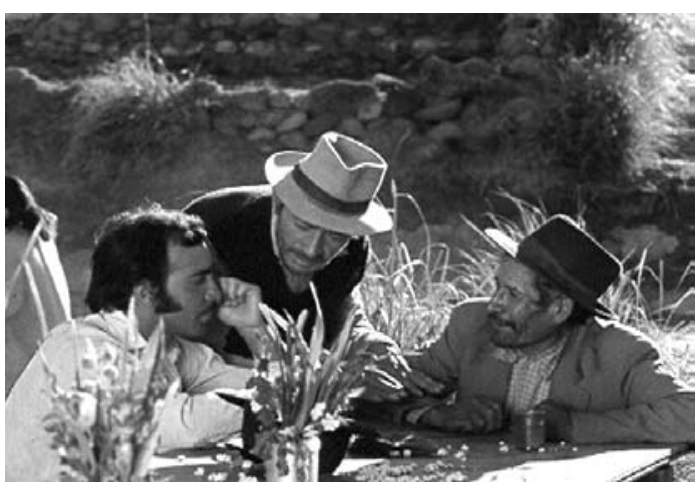

Figura 2. Fotograma de A la Sombra del Sol (Caiozzi y Perelman 1974).

Frame of A la Sombra del Sol Film (Caiozzi and Perelman 1974).

acumular riqueza, pero se les exhibe disfrutando de un paraíso terrenal pleno de recursos, desde donde sólo basta recolectar. En el cine chileno, el nativo es sinónimo de una sociedad satisfecha.

El sentido común dicta que el sonido en un filme no debería ser parte de estos procesos, pero en tanto las bandas sonoras son el resultado de operaciones prefílmicas, de rodaje y edición, cabe poca duda que es un atributo que es instalado de manera semejante a los atuendos o escenarios. También aquí se aprecian regularidades, y no sólo porque en todos los filmes hay cantos o música autóctona, sino porque todas han evitado esa convención del western norteamericano de la década de 1950, películas donde los nativos hablaban en el mismo idioma que el realizador (Carreño 2006). Wichan y El Cautiverio Feliz son habladas en mapudungun y A la Sombra del Sol (aunque doblada por actores) respeta ese español antiguo tan propio de la gente de la región. Problemas aparte plantean Archipiélago y Tierra del Fuego, en especial porque no existen sobrevivientes o personas que hablen estos idiomas en la actualidad. Quizás por esto en la película de Perelman los nativos nunca hablan, solo ríen o murmuran a lo lejos. Más curiosa resulta la solución dada por Littin, donde sus actores simulan el lenguaje selk'nam. Sin embargo, al no aparecer subtitulado se deja en evidencia su carácter desconocido. Ambas fórmulas revelan la extraordinaria fuerza de una convención de vestidura e investidura, que a nivel del sujeto y lo social no expresan diferencia y alteridad, sino simplemente ese tipo de exotización que impide revelar los contenidos culturales que distinguen en propiedad al otro.

\section{Montaje 2: el relato}

El relato o historia en una obra cinematográfica puede ser examinado poniendo atención en el contenido de lo relatado (diégesis) o en el modo en que este contenido nos es relatado (narración) (ver Stam et al. 1999:91 y ss).

En términos de diégesis, los relatos en todos los filmes adquieren una forma épica, es una lucha entre héroes de signo contrario. Poca duda cabe que los nativos son mejores que nosotros, pues son representados estableciendo modos de convivencia social donde los individuos son libres de las asimetrías e injusticias propias de nuestra sociedad. En A la Sombra del Sol y Wichan, el mensaje es la justicia verdadera; en Cautiverio Feliz es la generosidad, la tolerancia y el respeto por el otro; en Archipiélago y Tierra del Fuego es la inocencia perdida.

El dictamen jurídico y moral es un contenido manifiesto, una práctica cultural que no puede evitar un segundo contenido, que sólo por comodidad llamaremos latente. En este nivel, los contenidos (y los artefactos mismos) son reveladores de su dependencia con la Historia, pues es bastante obvio que ellos proyectan contenidos sociales y culturales arrancados de los imaginarios de su época. A la Sombra del Sol y Wichan son casos iluminadores al respecto, pues como sus realizadores nos testimoniaron, consciente e inconscientemente, filtraron en sus obras aspiraciones de justicia que discutían los modelos imperantes en las décadas de 1970 y 1980 , respectivamente. Caiozzi y Perelman, sin desearlo abiertamente (lo contrario habría sido absurdo, pues era el primer año de dictadura militar), promovieron en su filme el tema de la justicia popular, una de las reivindicaciones programáticas de mayor prestigio durante el gobierno del presidente Salvador Allende (Gallardo 2007). Al contrario de estos realizadores, Maga Meneses eligió para su filme un pasaje de las memorias del cacique mapuche Pascual Coña, justamente por su figura jurídica, pues en su opinión allí se describía un tipo de justicia humanitaria y pacífica de la que debíamos aprender. Una reacción fácil de comprender, luego de 16 años de violaciones a los derechos humanos, en un país donde la violencia era el equivalente de gobierno.

Si la diégesis en estas películas es sugerentemente moralizadora, la narración otorga al tiempo un significado particular, suspende el acontecimiento entre lo histórico y lo mítico. En todas ellas se alude a una fuente histórica que opera como un recurso 
de autenticidad: los testimonios de los habitantes de Caspana (A la Sombra del Sol), los objetos etnográficos y la secuencia documental (recreada) del salesiano Alberto de Agostini (Archipiélago), las memorias de Pascual Coña (Wichan), el libro de Núñez de Pineda (Cautiverio Feliz) y el diario de Julius Popper (Tierra del Fuego).

Se trata de citas de autoridad que permiten validar la realidad de los eventos visualizados, un recurso de lo verosímil clave en el género documental, obras que recurren a la realidad como fuente de un discurso audiovisual que nunca es ajeno a la visión del realizador y los imperativos de su contexto sociocultural (Raurich 2006). Sin embargo, sabemos que estas obras no son documentales, y tal vez por esto todas remodelan la coordenada histórica introduciendo una segunda temporalidad. En A la Sombra del Sol los realizadores tuvieron especial cuidado en dejar fuera de sus planos calendarios, anuncios publicitarios, el tendido eléctrico o cualquier otro elemento que aludiera al momento de la realización. Todo dentro de la película evoca un pasado reciente, pero nada nos ayuda a precisar una fecha con exactitud. Algo semejante ocurre en Wichan, donde una ligera ambientación de época y un reemplazo del color por el blanco y negro provocan un efecto semejante (Figura 3).

En las películas restantes, este procedimiento narrativo de ambigüedad es logrado por otros medios, aunque con resultados no menos efectivos.

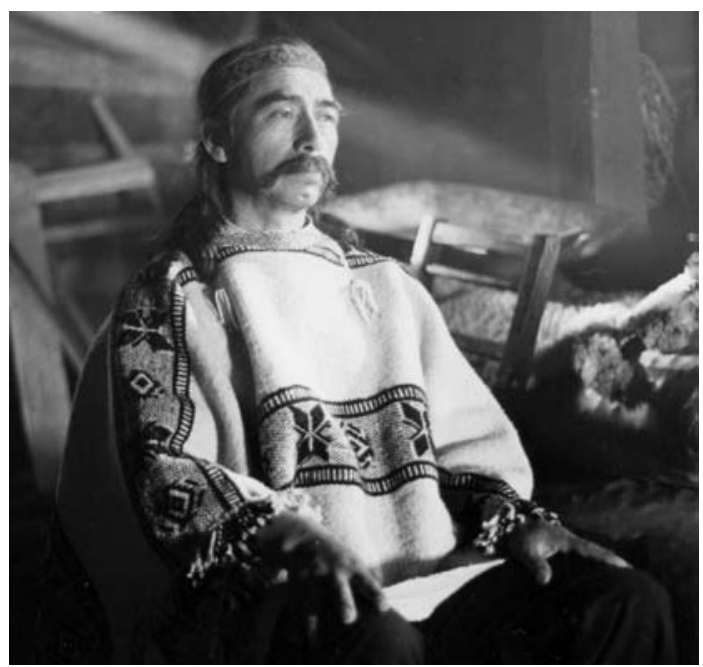

Figura 3. Lorenzo Aillapán vestido como lonko en Wichan, el Juicio (Meneses 1994).

Lorenzo Aillapán costumed as lonko in Wichan, el Juicio (Meneses 1994).
Todas ellas exhiben, con mayor o menor despliegue de recursos, una ambientación que sitúa al nativo en la época de contacto. Escenarios, vestimentas y utilería contribuyen a precisar una cronología. La relación de los eventos con la memoria y la oralidad (A la Sombra del Sol y Wichan); la agonía de un moribundo (Archipiélago); el relato de Núñez de Pineda (Cautiverio Feliz) y los recuerdos de Armenia, la amante del protagonista (Tierra del Fuego), curva el tiempo de lo narrado introduciendo al nativo en la bruma de lo soñado, la contemplación de algo fosilizado.

En la totalidad de las obras hay un ejercicio de exclusión, una operación que fisura el continuo de los acontecimientos históricos para depositar el relato en un tiempo que huye de su realidad y temporalidad objetiva, que da un salto a ese dominio donde la palabra (la imagen en este caso) era anterior a lo existente. Refiriéndose al uso del blanco y negro en su película, Maga Meneses llamó a esto provocar el efecto de "un tiempo sin tiempo", una descripción apropiada para ese procedimiento que evoca poderosamente ese "Había una vez" de los cuentos para niños, que como sabemos no son un simple medio de entretenimiento sino de instrucción cultural ${ }^{3}$. Poca duda cabe, que estos ejercicios fílmicos se han colocado al interior de las fronteras del mito, que para Lévi-Strauss (1970:189) no sólo se refiere al pasado, sino simultáneamente al presente y al futuro, pues supone una estructura cuya eficacia es pertinente a lo actual y el devenir posible del acontecimiento histórico.

El eje paradigmático o estructural en estas películas se dispone sobre la oposición primitivo/ civilizado que, a diferencia de la versión decimonónica que coloca estos términos en una escala de "progreso", ahora aparece organizada en una escala de "moralidad", donde se oponen valores como: el bien y el mal, lo justo y lo injusto, el equilibrio y el desequilibrio (Tabla 1). Nada bueno, justo o socialmente equilibrado puede esperarse de "nosotros", de nuestro estilo de vida, por el contrario las formas de convivencia del otro (económicas, políticas, religiosas o artísticas) son ejemplares. Ellos son el reverso de lo que somos, pero ese "nosotros" al que se hace referencia no es cualquiera, es una categoría social limitada a la clase económicamente dominante y sus agentes. Los enemigos clásicos del proletario y el campesino, que en estos filmes son ahora reemplazados por el nativo. Se trata de un cine de denuncia por omisión. 
Tabla 1. Oposiciones básicas en los filmes chilenos analizadas.

Oppositions in Chilean films.

\begin{tabular}{lll}
\hline Filmes & Valor Negativo & Valor Positivo \\
\hline A la Sombra del Sol & Delincuentes & Atacameños \\
Archipiélago & Conquistadores & Chonos \\
Wichan & Carabineros & Mapuches \\
Cautiverio Feliz & Conquistadores & Mapuches \\
Tierra del Fuego & Terratenientes, buscadores de oro y mercenarios & \\
\hline
\end{tabular}

En la imaginación de los realizadores chilenos (y todos aquellos que comparten su doxa), ya no es el proletario o el campesino el que proporcionará esa sociedad satisfecha que ofrecía el socialismo real, sino más bien el nativo, pues "objetivamente" (algo dictado por su sentido común) éstos han vivido de este modo en el pasado.

Los valores asignados a los nativos en los filmes chilenos son los valores atribuidos a las clases explotadas, según las definiciones de las teorías sociales del siglo XIX. En estas, los proletarios -y más tarde los campesinos- eran los héroes culturales de una historia futura donde prevalecería la justicia social. El derrotero de este proyecto es bien conocido por todos, y es sorprendente que -simultáneamente al ocaso histórico de la creencia acerca del protagonismo de esa figura social-comience a operar un proceso de transferencia que introduce al nativo como una nueva forma de reflexión cinemática. Se podría decir que, para un sector de los intelectuales -especialmente aquellos que se sienten incómodos con las clases dominantes-, el nativo se vuelve el refugio de una forma utópica de imaginar la libertad.

Este mito y su temporalidad trabajan con el fracaso y la frustración. Es la interiorización simbólica de la derrota de la "vía chilena al socialismo", un modo nostálgico que condena a "la lucha de clases" a no terminar nunca. En el imaginario de estas películas, la historia deja de ser proceso, vuelve una y otra vez al punto de partida, se congela en un "tal vez", en un "quizás".

\section{Epílogo}

El cine es un arte, por lo cual todo lo que está en el mundo le pertenece como material de trabajo, placer y reflexión (p.ej. Debrix 1971). La validez o la importancia de sus enunciados no pertenecen a la epistemología de la ciencia. Sin embargo, en tanto sus comentarios se desenvuelven en el teatro del imaginario es evidente que sus productos son cultura objetivada. Para la antropología esto representa una responsabilidad y la apertura de un nuevo campo de indagación, pues el cine desde su propio campo intelectual se ha hecho cargo de darle curso material a las miserias y grandezas de lo inmaterial, a esos valores y creencias que desde su actualidad disputan algún tipo de verdad simbólica y social ${ }^{4}$.

Más de 100 años de ejercicio cinematográfico han modelado y remodelado nuestra memoria visual, nos han introducido en un universo de convenciones que les ha permitido -desde las historias cortas de los hermanos Lumiére en 1895-articular sus dispositivos y procedimientos en una retórica que consumimos como relatos. Su relación con la literatura puede ser polémica, pero es incuestionable. Por consiguiente, aunque es un hecho que los nativos aparecen proyectados en la pantalla, no es menos cierto que bajo el contexto de una narración la imagen de ese nativo es sedimentaria, es una huella que finalmente sólo puede ser comprendida como función y acción. Es claro que estos atributos narrativos provienen de un modelo cultural compartido por los realizadores, una doxa que aparece dominada por el contexto histórico y social de las realizaciones.

La imagen del otro en el cine chileno ha devenido en exotización, ha sido vaciada de su contenido inherente ${ }^{5}$. Si en A la Sombra del Sol y Wichan el nativo exhibía una imagen de sobriedad campesina, las películas más recientes lo han modelado como un ser extravagante, vestido, ataviado, resignificado. Un montaje de la apariencia que por mostrar demasiado, no nos ayuda a ver el self del sujeto. Más aún, el nativo del cine chileno no es un ser en el mundo, es un signo, un ícono, un objeto de colección depositado en un museo. Es la constatación de algo que pudo haber existido, congelado en un tiempo que no ha devenido, que permanece en la lejanía de lo inmemorial. Este procedimiento es pasmosamente 
semejante a la reacción posmodernista descrita por Jameson $(1999: 22,25)$ como respuesta al fracaso de los proyectos de la modernidad: un síntoma alarmante y patológico de una sociedad que se encastilla en el pasado y no es capaz de enfrentar el ahora del tiempo y la historia.

La función de este nativo fílmico es inversa, él es lo que no somos. Sin embargo, para hacerlo es sometido a un doble proceso de envejecimiento, pertenece al pasado histórico y al mismo tiempo a un pasado mitificado. De esta manera, el presente de lo posible (del narrador y el narrado) es negado e invisibilizado. Lo real, lo que existe en proceso, deviene en trauma de una mismidad incapaz de concebir que nosotros y los otros estamos deviniendo ahora en otros.

Agradecimientos: al Fondo Nacional de Ciencia y Tecnología (Proyecto 1030029). A mis colegas Margarita Alvarado, Gastón Carreño, Felipe Maturana, Juan Pablo Silva, Guillermo Molina, Valentina Raurich, María Paz Bajas, María Paz Peirano y Samuel Linker. A los directores Silvio Caiozzi, Maga Meneses, Pablo Perelman y Cristian Sánchez, quienes generosamente nos proporcionaron información acerca de sus películas y su realización. Y finalmente a mis comentaristas anónimos, quienes detectaron importantes problemas de exposición.

\section{Referencias Citadas}

Arnheim, R.

1986 [1957] El Cine como Arte. Ediciones Paidós, Barcelona.

Bazin, A.

1966 ¿Qué es el Cine? Ediciones Rialp, Madrid.

Berger, J.

2002 Modos de Ver. Editorial Gustavo Gili S.A., Barcelona.

Bourdieu, P.

1977 Outline of a Theory of Practice. Cambridge University Press, Cambridge.

Bordwell, D.

1996 La Narración en el Cine de Ficción. Ediciones Paidós, Barcelona.

Carreño, $\mathrm{G}$.

2006 Pueblos originarios en el cine chileno: reflexiones sobre la construcción de dispositivos visuales. Boletín del Museo Chileno de Arte Precolombino 11:33-43.

Coloane, F.

1956 Tierra del Fuego. Editorial del Pacífico, Santiago.

Coña, $P$.

2000 [1930] Lonco Pascual Coña ñi Tuculpazugun Testimonio de un Cacique Mapuche. Pehuén, Santiago.

Chion, $\mathrm{M}$.

1992 El Cine y sus Oficios. Ediciones Cátedra, Madrid.

Debrix, J.

1971 The Cinema as Art. Penguin Books, England.

Eisenstein, $\mathrm{S}$.

1977 Anotaciones de un Director de Cine. Editorial Arte y Literatura, La Habana.

Gallardo, F.

2007 "A la Sombra del Sol" y la penumbra de los tiempos de la historia. Estudios Atacameños 33:125-132.

Gamerro, C. y P. Salomon, compiladores 1993 Antes que en el Cine. La Marca Editora, Buenos Aires. Godoy, M.

1966 Historia del Cine Chileno. Imprenta Arancibia, Santiago.
Jameson, F.

1984 Postmodernism, or the cultural logic of late capitalism. New left review 146:53-92.

1995 La estética Geopolítica. Ediciones Paidós, Barcelona. 1999 El postmodernismo y la sociedad de consumo. En El Giro Cultural, pp. 15-38. Manantial, Buenos Aires.

Lévi-Strauss, C.

1970 La estructura de los mitos. En Antropología estructural, pp. 186-210. Editorial Universitaria de Buenos Aires, Buenos Aires.

Mason, $\mathrm{P}$.

1998 Infelicities: Representations of the Exotic. The Johns Hopkins University Press, Baltimore.

Mege, $\mathrm{P}$.

1991 La imagen de las fuerzas: ensayo sobre un mito mapuche. Boletín del Museo Chileno de Arte Precolombino 5:9-22.

Metz, C.

2002a Ensayos sobre la Significación en el Cine. Volumen 1. Ediciones Paidós, Barcelona.

2002b Ensayos sobre la Significación en el Cine. Volumen 2. Ediciones Paidós, Barcelona.

Mirzoeff, N.

2003 Una Introducción a la Cultura Visual. Ediciones Paidós, Barcelona.

Muesca, J. y C. Orellana

1998 Cine y Memoria del Siglo XX. LOM Ediciones, Santiago.

Nichols, B., editor

1985 Movies and Methods, Volume II. University of California Press, Berkeley.

Núñez de Pineda y Bascuñán, F.

1999 [1674] El Cautiverio Feliz. Biblioteca Virtual Miguel de Cervantes, Alicante. 
Panofsky, E.

2000 [1947] El estilo y el medio en la imagen cinematográfica.

En Sobre el Estilo. Tres Ensayos Inéditos, pp. 113-151. Ediciones Paidós, Barcelona.

Peirano, $\mathrm{M}$.

2006 Nosotros, los otros. Boletín del Museo Chileno de Arte Precolombino 11:55-66.

Powdermaker, $\mathrm{H}$.

1955 Hollywood: El Mundo del Cine Visto por una Antropóloga. Fondo de Cultura Económica, México D.F.

Pudovkin, V.

1948 Argumento y Montaje. Bases de un Film. Editorial Futuro, Buenos Aires.

1999 On editing. En Film Theory and Criticism, editado por L. Braudy y M. Cohen, pp. 9-14. Oxford University Press, New York.

Raurich, V.

2006 Más allá de la Ficción y la Realidad: El Documental y su Valor Simbólico. Memoria de Título para optar al Grado de Antropóloga, Departamento de Antropología, Facultad de Ciencias Sociales, Universidad de Chile.

Rollins, P.

1987 El Cine como Fuente Histórica. Editorial Fraterna, Buenos Aires.

Stam, R., R. Burgoyne y S. Flitterman-Lewis

1999 Nuevos Conceptos de la Teoría del Cine. Ediciones Paidós, Barcelona.

Villain, D.

1994 El Montaje. Ediciones Cátedra, Madrid.

Williams, R.

1980 Marxismo y Literatura. Ediciones Península, Barcelona.

Wead, G. y G. Lellis

1981 Film: Form and Function. Houghton Mifflin Company, Boston.

Wollen, P.

1972 Signs a Meaning en the Cinema. Indiana University Press, Bloomington.

\section{Filmes Citados}

Bussenius, G.

1917 Agonía de Arauco. Blanco y negro, 28 partes. Chile Films Co., Chile.

Caiozzi, S.y P. Perelman

1974 A la Sombra del Sol. Color, 70 min. DISA Films, Chile.

Coll, J.

1971 La Araucana. Color, 81 min. José Antonio Pérez Giner, España-Chile-Italia-Perú.

Francia, A.

1969 Valparaíso mi Amor. Blanco y negro, 90 min. Cine Nuevo de Viña del Mar, Chile.

Idiáquez, R.

1925 Nobleza Araucana. Blanco y negro, Rex Films, Chile.

Kaulen, P.

1967 Largo Viaje. Blanco y negro, 90 min. Soc. Naranjo y Campos, Chile.

Kramarenko, N.

1957 Tres Miradas a la Calle. Blanco y negro, 80 min. Procine, Chile. Menéndez, Chile.
Littin, M.

1969 El Chacal de Nahueltoro. Blanco y negro, 88 min. Cine Experimental de la Universidad de Chile / Cinematográfica del Tercer mundo / Erco Films, Chile.

2000 Tierra del Fuego. Color, 106 min. Castelao Productions / Surf Films / Buenaventura Films, España-Italia-Chile.

Margas, L.

1971 Frontera sin Ley. Color, Fílmica Panamericana Ltda., Chile.

Meneses, M.

1994 Wichan: El Juicio. Blanco y negro, 25 min. Kien Producciones, Chile.

Perelman, P.

1992 Archipiélago. Color 77 min. TVE S.A. / Ima Films / Chanel 4, Chile.

Sánchez, C.

1998 Cautiverio Feliz. Color, 143 min. Nómada Producciones, Chile.

\section{Notas}

1 Este tipo de artificialidad fue condenado por el cine europeo de postguerra, el cine independiente norteamericano de los sesenta y más recientemente por el grupo Dogma. Ellos y otros cineastas de ficción han propiciado un alejamiento del guión, favoreciendo la improvisación y centrando el proceso creativo en el rodaje y adición del filme.

2 Sobre estas operaciones culturales ver Wead y Lellis (1981) y Williams (1980).

3 "Hay mitos que son cuentos, no son narrados para demostrar, sino para educar ejemplarmente. Enseñan en el drama, involucran sutilmente a los que escuchan en una dimensión particular del pensamiento. Los eventos que se narran parecen inofensivos, pero esconden siempre una intencionalidad cultural: instruir, enculturar. La eficacia de un buen cuento reside en desarrollar un relato mitológico sin moralizar y sin explicitar de manera muy evidente la intención pedagógica que oculta el drama” (Mege 1991:9).

4 El concepto de campo intelectual lo he tomado de Bourdieu (1967).

5 Sobre el concepto de exotización ver Mason (1998). 
ANDROS IMPRESORES

www.androsimpresores.cl 